\title{
A Nationwide Planning of Analytical Chemistry in Universities: Possibilities and Problems*
}

\author{
R. Visser \\ Department of Chemical Technology, Twente University of Technology, \\ NL-7500 AE Enschede, The Netherlands
}

\section{Allgemeine Planung für die analytische Ausbildung an Universitäten: Möglichkeiten und Probleme}

Zusammenfassung. Eine solche allgemeine Planung für die Analytische Chemie sollte zwei Forderungen erfüllen: die Aufstellung eines gemeinsamen Mindestprogramms für alle Universitäten und eine ausgewogene Verteilung der Forschungsthemen auf die verschiedenen Hochschulen. In den Niederlanden gehört diese Planung zu den Aufgaben des »ISOAN« (Intersubfakultäts-Beratung über Analytische Chemie). Obwohl bisher keine besonders auffallenden Ergebnisse erzielt wurden, konnte doch durch die Beratungen ein klares Bild der Analytischen Chemie und ein besseres gegenseitiges Verständnis erreicht werden.

Summary. A nationwide planning of Analytical Chemistry in universities should meet two requirements: formulation of a common minimum programme for all universities and a well-balanced spread of research themes over the different universities. In the Netherlands this planning is the object of "ISOAN", the Intersubfaculty Deliberation on Analytical Chemistry. Perhaps spectacular results have not yet been obtained, however thinking about these subjects has led to a more lucid picture and better mutual understanding.

Key words: Analytische Chemie; Planung für die Hochschulausbildung in den Niederlanden

The interest in a comparison of education levels in universities is increasing, especially because in many

* Presented at Euroanalysis III conference, Dublin, August 20-25, 1978 countries universities are forced nowadays to reorganize their curriculae. But also future employers are interested, at least some time ago a personnel manager of an important chemical industry gathered information how to relate the levels of Analytical Chemists in several European countries.

Although this may change in future, at the moment all university teaching programmes in the Netherlands are based on a two-stage system: a general programme with hardly any specialization during three to four years, followed by a second period of two to three years during which a mayor subject is chosen, e.g. Analytical Chemistry. The first period leads to a degree ("Kandidaatsexamen") which has no value in society, the second ends with a graduate examination ("Doctoraalexamen") yielding the title "drs." ("Doctorandus") or "ir." ("Ingenieur" or engineer) for those studying at a university or at a technological university, respectively. About $90 \%$ of the students leave the university by then, the remaining part goes on for a Ph.D. degree (about 4 years).

The first question is: what should every student know about Analytical Chemistry after a 3-4 years of study? Much more attention should be paid to this problem, also in those countries where no formal twostage curriculum exists. The second question is: what should the graduate in Analytical Chemistry look like?

The first question: we believe that every chemist should be able:

- to formulate his analytical problems, if not in specific analytical terms, then at least in his own wordings;

- to discuss these problems with a specialist and to understand the information he gets back, on the basis of a broad but surface knowledge of the principles and the most frequently used methods;

- to solve simple analytical problems with relatively simple means, in those cases where no specialist is available, e.g. in a small industry. 
It is interesting to note that in Switzerland more than half of recently appointed Analytical Chemists were not educated as such [3]. There is no reason to believe that the situation in other countries is much different.

Whereas in the past heavy industries based on locally available minerals, like the steel industry or coal mines, determined the character of chemistry in many countries, nowadays a great diversity of chemical industries is found in most countries. Furthermore, the hesitating economy, increasing unemployment among graduates, faster ageing of university education and increasing rate of function changes are factors demanding a flexible education. This leads to the following conclusions:

- every undergraduate chemistry curriculum should contain an obligatory programme in Analytical Chemistry;

- this programme should include, besides basic principles, a survey of frequently used methods, both organic and inorganic, both quantitative and qualitative;

- this programme should enable any chemist to communicate with specialists;

- at the same time it should form a basis for a specialized education in Analytical Chemistry, either in a graduate study or perhaps many years later in practice.

At this point it should be stated clearly that, even if some methods are dealt with by other university staff members (like e.g. nuclear magnetic resonance or mass spectrometry by organic chemists) these methods should be considered fundamentally as analytical methods. In fact, in industrial laboratories these techniques are frequently found in analytical departments. The sometimes observed aversion of spectroscopists to be considered as Analytical Chemists is probably based on a one-sided picture of Analytical Chemistry obtained during their study, more than on logic reasoning.

With regard to the graduate study in Analytical Chemistry a gradual development may take place in future towards two types of Analytical Chemists:

a) those having a highly specialized knowledge of one method or a group of closely related methods (e.g. atomic absorption spectroscopy or atomic spectroscopy);

b) those with a broad but not too superficial knowledge of many methods but with a special practice in what may be called "analytical management", including the selection of optimal strategies for the solution of analytical problems. (The differentiation between method oriented and problem oriented specialists has been left out for convenience.)

A discussion of the second type is presented by Kateman and Dijkstra [2]. One can expect that in future
Table 1. Model for a two level study in Analytical Chemistry

\begin{tabular}{|c|c|c|c|c|}
\hline \multirow[t]{2}{*}{$\begin{array}{l}\text { Graduate } \\
\text { study } \\
\text { (Analytical } \\
\text { Chemists only) }\end{array}$} & $\begin{array}{l}\text { Specialization } \\
\text { (including } \\
\text { project) }\end{array}$ & 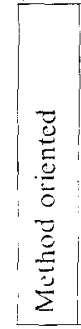 & 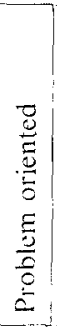 & 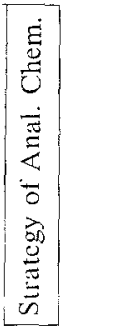 \\
\hline & Introduction & \multicolumn{3}{|c|}{$\begin{array}{l}\text { - Comparison and selection } \\
\text { - Analysis stritegy } \\
\text { - Costs }\end{array}$} \\
\hline \multirow[t]{2}{*}{$\begin{array}{l}\text { Under- } \\
\text { graduate } \\
\text { study } \\
\text { (All } \\
\text { students) }\end{array}$} & $\begin{array}{l}\text { Survey } \\
\text { of } \\
\text { methods }\end{array}$ & \multicolumn{3}{|c|}{$\begin{array}{l}\text { - Separation methods } \\
\text { (specially GLC) } \\
\text { - Titrimetry, potentiometry, } \\
\text { conductometry } \\
\text { - Atomic spectroscopy } \\
\text { (specially AAS) } \\
\text { - Molecular spectrometry } \\
\text { (IR/UV, NMR, mass } \\
\text { spectrometry) } \\
\text { - Photometry }\end{array}$} \\
\hline & Introduction & \multicolumn{3}{|c|}{$\begin{array}{l}\text { - Sampling } \\
\text { - Qualitative vs. } \\
\text { quantitative analysis } \\
\text { - Accuracy, reproducibility, } \\
\text { detection limits } \\
\text { - Simple statistics }\end{array}$} \\
\hline
\end{tabular}

elements of a study for a "Strategist-Analytical Chemist" will be incorporated in other courses of Analytical Chemistry.

It is not necessary and even undesirable to create a uniform curriculum for either level in one country, not to speak about Europe. Preferably, only a minimum framework should be formulated. A possible model for a two level study is presented in Table 1.

It seemed interesting to compare the criteria mentioned above with the actual situation.

Therefore an inquiry was set up into this situation at Dutch universities. Details of this inquiry will be published elsewhere [4].

The time spent on Analytical Chemistry in the undergraduate study shows the following ranges (in hours)

proper Analytical Chemistry courses $\quad 0-68 \mathrm{~h}$

Analytical Chemistry as part

of general chemistry

lectures total

$0-28 \mathrm{~h}$

practical courses

$0-77 \mathrm{~h}$

$130-380 \mathrm{~h}$

total

$100-400 h$ 
The percentage of Analytical Chemistry of the total undergraduate programme ranges from $10-20 \%$ (UK: $14 \%[1]$ ).

The topics dealt with show variations, but gas chromatography, titrimety, potentiometry are frequently mentioned, less attention is paid to sampling, data acquisition and data handling. Molecular structure analysis is sometimes presented as part of organic chemistry courses.

The results show rather much variation and more discussion will be necessary - also internationally - to formulate a minimum programme of Analytical Chemistry as mentioned above.

For the graduate courses again differences are found between the universities. However, the greatest problems are related to the projects and the postgraduate (Ph.D.) work. It is obvious that subjects of graduate work should - if possible - be connected to Ph.D. work in order to improve the research output. Now the following questions arise:

1. Should the number of research themes at each university be limited (e.g. to 1 or 2)?

2. Should the selection of these themes be made on the basis of the autonomy of the universities, or as the result of a coordinated national planning?

3 . Is the choice of these themes inseparably connected with the presence of a professor (or reader), and with his specialism?

These questions have been discussed for many years in the "Intersubfaculty Deliberation on Analytical Chemistry" ("ISOAN"). However, the problem seems to be of more than national importance. Universities in many countries are confronted with decreasing staff and funds. Still a high output of scientific work is expected. Most research work is presented in international journals and on international symposia. Here the national interests meet one another, the standards are set and the image of Analytical Chemistry is determined.

Though no definitive opinion has been formulated yet, a nation-wide planning should be based upon the following starting-points:

- every chemistry department needs at least one chair in Analytical Chemistry;

- the number of research themes at each university should not exceed the number of chairs by more than one;

- every research area should at least be represented at one university;

- not too many universities should work in the same area.

Is it necessary indeed to spread the interest over the whole field of Analytical Chemistry? The most important positive arguments are: in this way the needs of industry (employers in general) are best met, the specialized centers can disseminate information (can act as "centers of gravity", e.g. for refreshing courses) and finally: if the analytical institutes do not do the job, who else would do it?

In the Netherlands nearly all universities have one or more chairs of Analytical Chemistry. Besides the fact that separation methods are somewhat overrepresented a reasonable spread over the whole field is observed. Problems may arise in the future. A few things to be undertaken are:

- One or more members of the national deliberation should be appointed in "profile" or selection committees to fill vacancies.

- Chemistry departments should be urged to support the nationwide planning even if this is not consistent with their own ideas.

- Analytical institutes should be subordinate to this planning as well. However, room must be left for innovative ideas.

In practice only few students tend to change their university during study. If so, the social problems they have to expect (new housing, new friends) seem to surpass by far the educational difficulties (provided that a uniform minimum programme is taught).

Finally a more personal remark. At some universities so-called "integrated practical courses" have been introduced. In these courses different aspects of chemistry are combined in one problem, e.q. synthesis of a compound followed by its analysis and physical characterization. In spite of the less intensive specific training a better practice is obtained. A great advantage is the intensive cooperation and much better mutual understanding of experts in different disciplines during preparation and running of these courses.

In conclusion it can be stated that a national deliberation as described above is worthwhile. Perhaps spectacular results have not yet been obtained, however a more lucid picture of Analytical Chemistry, also in relation to other chemistry subdisciplines is being created.

\section{References}

1. Education and Training Committee: Proc. Anal. Div. Chem. Soc. 14, 1 (1977)

2. Kateman, G., Dijkstra, A.: Fresenius Z. Anal. Chem. 297, 249 (1979) (this same special issue)

3. Siegwart, Y.: Fresenius Z. Anal. Chem. 297, 278 (1979) (this same special issue)

4. Visser, R. : Fresenius Z, Anal. Chem. 297, 308 (1979) (this same special issue)

Received November 3, 1978 